\title{
Debate
}

\section{Social capital-Is it a good investment strategy for public health?}

In a recent commentary in the fournal, Fran Baum raised the question, whether social capital is "good for your health?" While the concept of social capital has had a meteoric rise in political, economic and public health rhetoric it remains to be fully defined and understood. ${ }^{23}$ Despite this lack of clarity, there has been the release of government and World Bank discussion papers, the staging of theme conferences and the growing use of the terms social capital, social cohesion, and civil society-all being promoted as beacons to guide public health research and practice-even though no clear, shared definition exists about what the concepts actually mean.

In the sociological literature the domain covered by the term "social capital" has been highly elastic. ${ }^{3}$ In some instances, social capital has by definition been beneficial or "good" in some way, while in others, the idea that one group's social capital can be another group's oppression has been accepted. Social capital has been used to refer to both formal and informal reciprocal links among people in all sorts of family, friendship, business and community networks. Where social capital resides-in the persons or groups linked by these networks? in the networks themselves? in the communities within which these networks exist? - is unclear. Ironically, the discourse around social capital in the health field often has a less fully socialised perspective than classic ideas about physical and financial capital being rooted in social relations of production. ${ }^{4}$ Such under-theorised applications in health research have lead to social capital being applied as a new and more fashionable label for investigations in what used to be called the "social support" field. ${ }^{5}$ Nevertheless, social capital and social cohesion have been proposed as the most important mediators of the association between income inequality and health. ${ }^{67}$

So, amid this epidemic of social capitalism, Baum's commentary is a welcome caution, because she illustrates some of the definitional, measurement and interpretive problems associated with the concept. Although an advocate of the idea, ${ }^{8}$ Baum suggests that having an unsophisticated understanding of social capital masks the fact that more social capital is not necessarily an unmitigated good. What Simon Szreter has called "sectional social capital" (personal communication), may be corrosive for a whole society. For example, levels of social capital may be high within the National Rifle Association or the Mafia, but is this good for public health? Similarly, while a tight knit network of injecting drug users may under certain conditions provide social support, ought we to not also be concerned about the health consequences of what else is being exchanged over those networks? Scratch beneath the surface of social capital and things get complicated rather quickly.

In a thoughtful review about the links between social capital and economic development, Woolcock has argued that the concept of social capital " ... risks trying to explain too much with too little." (page 155). ${ }^{9} \mathrm{He}$ says that the term social capital is being " ... adopted indiscriminately, adapted uncritically, and applied imprecisely." (page 196). ${ }^{9}$ Is this criticism also true for the way social capital is being used in health research? Perhaps, but what is already clear from existing research, is that more social capital is not always good for health. There is a growing recognition of the complexity and contextual dependency of social relations and their meaning for health. ${ }^{10-12}$ Individual level studies show how strong networks of peers, family and friends can be sources of relational strain, with ambiguous health consequences. ${ }^{13}$

Notwithstanding these reservations, we wholeheartedly agree with Baum that a focus on social and economic causation is central to improving public health in the 21 st century. Baum calls for a public health agenda "that is based on solid theoretical and empirical understanding of the relation between social capital, economic development, public policy and health". ${ }^{1}$ We would add that it should also be based on an awareness of the contingent nature of these relations and how they are expressed in different cultural, economic and political contexts. ${ }^{14} \mathrm{~A}$ broader economic and political approach to public health is clearly needed - the question is - what exactly does social capital add to that approach?

\section{Absolute income and life expectancy}

Overly simplistic interpretations of the links among social capital, economic development, public policy and health - in the end-may do a disservice to a progressive agenda for greater social justice and better public health. In this light, it is unfortunate that Baum perpetuates the idea that absolute income levels and material standards of living are not important for health in developed countries. Although she recognises that it is possible to achieve better health by strategic investments in public services such as education and primary health care, she refers only to poorer countries or regions as examples of this. In regard to wealthier nations she implies that it is not material, but psychosocial conditions that are most important. She states that, "One of the undisputed findings from Wilkinson's work is that there is no direct correlation between gross national product per capita and life expectancy in developed countries."1 Presumably, Baum is referring to Wilkinson's analysis showing no association between gross domestic product per capita (GDP/head) and life expectancy in 23 OECD nations. ${ }^{15}$ Based partly on this evidence, Wilkinson stated, that in contrast with expectations generated by a view that material conditions are of most importance "... the psychosocial effects of social position account for the larger part of health inequalities." (page 591). ${ }^{15} \mathrm{He}$ argued these psychosocial effects were manifested directly through physiological responses to chronic stress, and indirectly through stress induced behaviours like smoking, excessive eating and drinking.

Figure 1 shows the association between GDP/head adjusted for \$US Purchasing Power Parity and life expectancy for 155 countries circa 1993. Estimates of GDP and life expectancy, and the selection of countries for which both these estimates are available, differ across data sources. However, we have included as many countries as possible by combining information from two reliable sources-GDP data are taken from the World Bank Development Indicators CD-ROM (1997), and life expectancy 


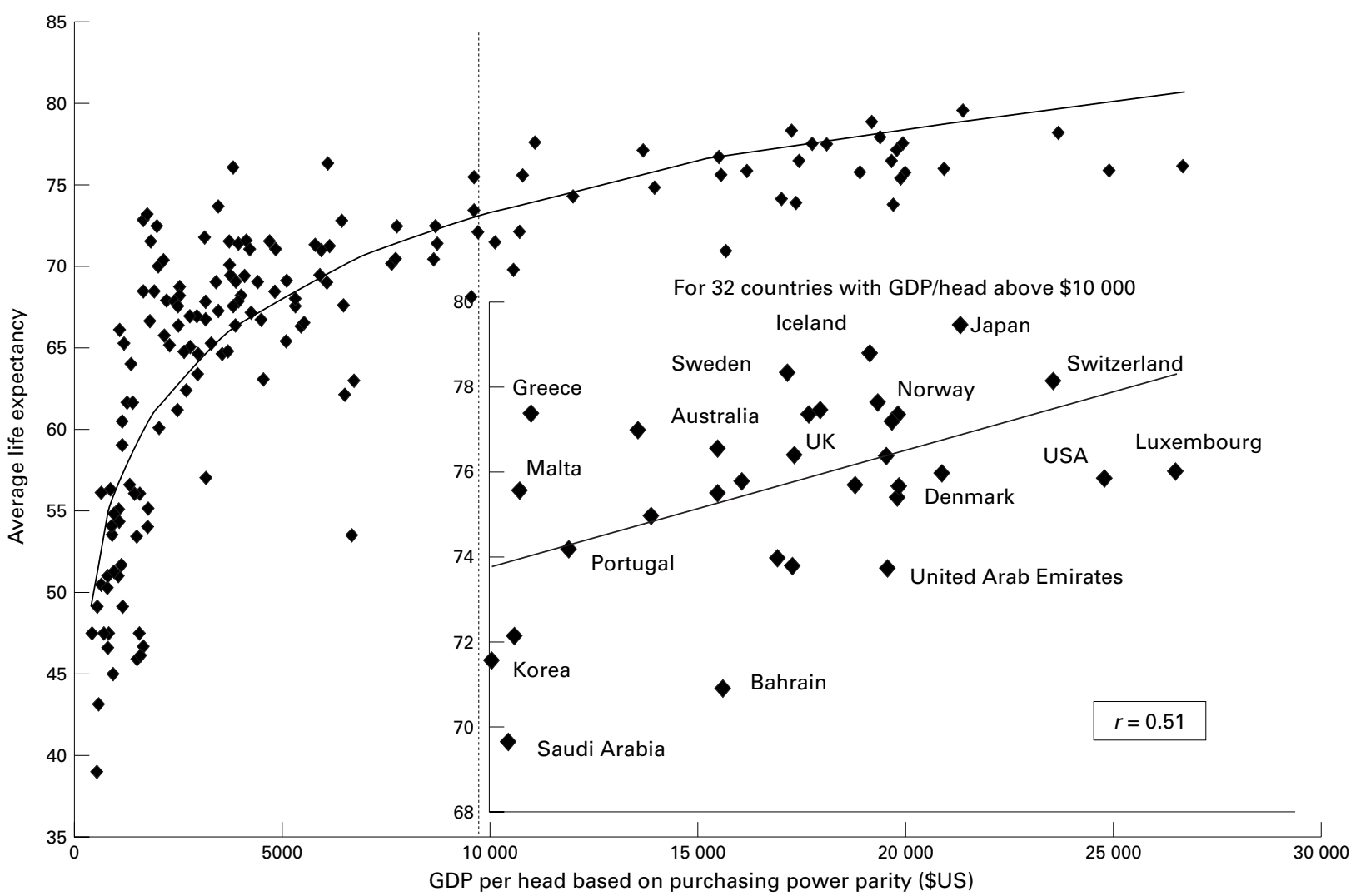

Figure 1 Association between GDP/head adjusted for \$US Purchasing Power Parity and life expectancy for 155 countries circa 1993.

estimates from the WHO statistical database (web site http://www.who.int/whosis/hfa/countries/index.html). The main figure shows the well known curvilinear association between GDP/head (a measure of average absolute income) and life expectancy. This association has been widely reported for different time periods and health outcomes. ${ }^{16}$ The inset in the figure isolates all countries where GDP/head was greater than $\$ 10000$. This is the same cut off for income level used in Wilkinson's analysis ${ }^{15}$ but our results are based on all wealthier countries, rather than a selection of some OECD nations. The correlation between life expectancy and GDP/head in this sample of 33 wealthier countries is $r=0.51(\mathrm{p}=0.003)$. The overall relation between GDP/head and life expectancy is clearly one of diminishing returns, but a correlation of this magnitude among wealthier countries would seem to qualify as evidence of a direct association. Our objective here is not to quibble about the empirical evidence. As we have indicated, even for the same year, GDP and life expectancy estimates do vary across data sources. Rather, our point is to show that the strength of association between absolute income and life expectancy seems quite sensitive to which countries are included. What constitutes an appropriate set of countries for comparisons of this sort is certainly open to debate. Nevertheless, we have shown that compared with Wilkinson's selection of 23 countries, the addition of the other 10 equally wealthy nations that constitute the full sample, significantly changes the results. Moreover, even within-country analyses have shown that absolute income levels remained a significant predictor of mortality, after adjustment for income inequality. ${ }^{17}$ The point here is that it is premature to dismiss the existence and importance of a direct association between absolute income and health status among developed nations. This becomes more obvious if the cumulative influence of material circumstances across the lifetime of people living in particular countries are considered, rather than simply cross sectional associa- tions between population level material conditions at one point in time and health outcomes. By implication this reinterpretation of data on determinants of population health also means that it may be misleading to claim greater public health importance for psychosocial rather than material factors.

\section{Absolute income, income inequality and indicators} of social capital

The importance of absolute income is also revealed in other analyses where we examined associations between GDP/head, the Gini coefficient of income inequality (from the Luxembourg Income Study), and data on levels of trust, belonging to organisations (such as churches, cultural organisations, etc), doing unpaid work for these organisations, and trade union membership taken from the World Values Survey. ${ }^{18}$ For 15 developed countries with comparable income data (France, Britain, Italy, Netherlands, Denmark, Belgium, Spain, USA, Canada, Hungary, Norway, Sweden, Finland, Poland, and the Czech Republic), we found that levels of trust, belonging to organisations, and doing unpaid work for such organisationsmeasures that have been proposed as indicators of social capital-were all more strongly related to GDP/head, $(r=0.74(\mathrm{p}=0.003)$ for trust; $r=0.67(\mathrm{p}=0.02)$ for belonging to organisations; and $r=0.86(\mathrm{p}<0.001)$ for unpaid work for those organisations), than they were to income inequality $(r=-0.18 \quad(\mathrm{p}=0.55) ; r=-0.36 \quad(\mathrm{p}=0.27) ;$ and $r=-0.06$ $(p=0.87)$ respectively). In contrast, levels of trade union membership were more strongly associated with income inequality $(r=-0.68, \mathrm{p}=0.02)$ than $\mathrm{GDP} /$ head $(r=0.16$, $\mathrm{p}=0.63$ ). Additionally, Diener and colleagues have shown in international comparisons that absolute income is a better predictor of subjective well being than relative income and conclude that, “... exposure in natural settings to others who are better off will not automatically influence one's moods in a negative way." (page 862) ${ }^{19} 20$ 


\section{The psychosocial environment hypothesis and health inequalities}

We are not advocating neoclassical "growth at all costs" economic policy. Our goal is to ground any discussion of the links between absolute income, income inequality, social capital and health in the primacy of the material, institutional and political causes of health inequalities. The purported lack of association between average income and health among developed countries has been used as a springboard for two related and extremely influential ideas. Firstly, that it is "relative", not absolute income that is most strongly related to health. ${ }^{15}$ While we are not opposed to this idea in principle, we are yet to be convinced by empirical or theoretical arguments regarding what researchers believe "relative income" is actually measuring, and how it affects health. Indeed, some of the writing about these mechanisms-generally in terms of abstract formulations regarding how psychological, neurological, endocrine and immune systems interact-essentially replaces one metaphor for another, rather than entering into a discussion of plausible causative links between social phenomenasupposedly indexed by "relative income" and health. The utility of basing a fundamental understanding of health inequalities on these psycho-neuro-endocrine mechanisms has even been questioned by one of the eminent researchers whose work with baboons is regularly cited in support of this approach. Robert Sapolsky has stated that, "A prime revisionist emphasis of this chapter has been how little, in fact, rank per se predicts any of those endpoints. Instead, it seems virtually meaningless to think about the physiological correlates of rank outside the context of a number of other modifiers - the sort of society in which the rank occurs ...”. (emphasis in the original) (page 39) ${ }^{21}$

The second assertion is that material conditions only exert weak health effects. According to this line of thinking, if absolute income is of lesser importance to health than relative income, then material standards of living cannot explain much of the observed variation in health status. ${ }^{6}$ Thus, it is the psychosocial effects of "perceptions of relative income" that are important. Perceptions of relative income are portrayed as individual psychological processes that generate lack of self respect, stress and negative emotions. Pathologically, these psychological processes are translated "inside" the person into poorer health through the mechanisms mentioned above. At the same time, these perceptions of relative position and the negative emotions they foster are translated "outside" the person into interpersonal distrust, reduced reciprocity, and eventually less social capital and cohesion within the community. In this way, perceptions of relative income have both negative biological consequences for people and negative social consequences for how people interact. Thus, perceptions of relative income serve as the explanatory focus linking individual and social pathology. ${ }^{6}$ This emphasis on individual level psychological perceptions and their physiological expression is not new and is widely evident in health research. However, it has become increasingly influential as the dominant lens through which social inequalities in health should be viewed. ${ }^{22-25}$

In adopting this approach, proponents of a mainly psychosocial theory of health inequalities have, to varying degrees, disconnected the psychological from the material-perpetuating the idea that psychological responses can be meaningfully understood as distinct from material aspects of life. We do not support this view. Psychological responses do not spring de novo from people - they reflect lived day to day experiences, and these experiences reflect material aspects of life that are politically, economically and culturally contingent. ${ }^{2} \mathrm{We}$ believe it is a mistake to conflate the structural sources of
KEY POINTS

- Based on limited conceptualisation and empirical evidence, claims concerning the public health utility of the concept of social capital may have been exaggerated.

- The empirical evidence used to downplay the public health importance of material factors, in favour of mainly psychosocial explanations, may be overstated.

- Indicators of social capital used by health researchers are not related to income inequality in international comparisons.

- Even if it were confirmed, a psychosocial theory of health inequalities based on "perceptions of relative income" has limited practical relevance in efforts to reduce socioeconomic inequalities in health.

- To maximise its importance for public health, social capital must be seen as a product of broadly defined social relations, rather than as a primarily psychological construct.

health inequalities with perceptions of their consequences. We certainly do not deny that social inequality has psychosocial costs for individuals, or that these negative psychosocial effects are an important topic for public health. ${ }^{26} \mathrm{~A}$ singular focus on perceptions of "relative income" however, can hide differences in real income, especially at the bottom of the income distribution where the greatest burden of ill health exists. For instance, in the richest five US metropolitan areas in 1990, the bottom $10 \%$ of the income distribution - that is, their relative income position, was defined by an income below $\$ 12000$ per year. In the poorest five areas, the bottom $10 \%$ was defined by incomes less than $\$ 4000$. The same relative income position masks large differences in real income. It is hard to accept that these absolute income differences and their implications for material standards of living are unimportant for health.

Under a primarily psychosocial model, health differences between these rich and poor areas are best understood as reflecting feelings of worthlessness, distrust and breakdown of social networks. A more material perspective opens the possibility that differences in absolute and relative income among areas may be indexing something as concrete as not having access to a car, in an environment where there is little or no public transportation, to deliver people to a place where they might sit and wait for hours to obtain the most basic health care. Under these sort of real world material conditions, it is almost unremarkable that people perceive unfairness and disrespect. In more general terms, we are saying that absolute and relative income differences may represent the unequal distribution of the material conditions that structure the likelihood of possessing and accessing health protective resources; of reducing negative health exposures; and of facilitating full participation in the society. ${ }^{27}{ }^{28} \mathrm{We}$ consider that a model that sees health outcomes as the physical and psychosocial embodiment of influences from the material environment as more fruitful for understanding health inequalities, and more useful as a basis for public policy, than one that concentrates on individual psychological functioning and informal inter-personal relations.

\section{A neo-material basis for health in the 21 st century} The influence of "material conditions" on health is usually understood within the framework of the sanitary approach to public health that arose in response to 19 th century industrial society. In this view, material conditions meant a roof over one's head, adequate caloric content from food, 
safe water supply and the reduction of environmental hazards through waste removal. Certainly, these were the dominant material conditions in the 19 th century when life expectancy was about 40 years, and mortality was attributable to mainly infectious causes, and they remain highly relevant for the 21 st century and beyond in both rich and poor countries. Millions of children in the US still do not get enough to eat. ${ }^{29}$ But is it also possible there are an expanded set of material conditions relevant for morbidity and mortality dominated by chronic diseases, and in the attainment of current life expectancies of over 75 years? Housing that protects against extreme heat, cold and damp; pollution and toxics; access to firearms; medical care; exercise and a nutritious low fat diet are all "neo-material" conditions that influence longevity in the 21 st century. Even after basic material conditions are satisfied, additional improvements could conceivably produce gains in health. There is evidence that health is sensitive to fine gradations of material conditions within wealthy countries, ${ }^{30-32}$ as evidenced through living in better neighbourhoods, access to a car, home ownership, and having a home with a garden. While it is vital to understand the link between material conditions and public health, it must be emphasised that material conditions may be specific to a particular society and time period. The material requirements for a healthy life in a modern US city, such as having a car, might exceed the material standards in another culture or time period. Perhaps it is time to consider the neo-material basis for reducing health inequalities in the 21 st century. ${ }^{33}$

\section{Is social capital just social support at the community level?}

The framing of the questions, and the language that is used to discuss inequality, material living conditions, social capital and health has enormous implications for the development and implementation of public policy. The dominant view in public health is that denser social networks and more support are invariably better for health. This is a consequence of the basic conceptual model-the buffering hypothesis-that social support somehow protects against stress. ${ }^{5}$ However useful this approach may be in understanding the health benefits of social support at the individual level, it is a mind set and a language that is inadequate to use when discussing the health implications of social capital. If we are to limit our understanding of social capital to the idea that it is the population level analogue of social support for a person, we may miss an opportunity to use the concept of social capital as an heuristic and practical tool to advance a public health oriented policy agenda to reduce health inequalities.

In considering the way authors like Woolcock ${ }^{9}$ and Szreter $^{34}$ describe social capital, one is struck by the breadth and depth of their vision for the concept. They see enormous conceptual and strategic potential in social capital as a way of revitalising how we think about the multi-faceted nature of human economic activity. They go beyond a narrow view, that social capital is essentially about sets of informal, horizontal social networks and the development of norms of trust and reciprocity that might function as a basis for productive activity and, presumably, the promotion of health. They present a much broader picture, which includes consideration of formal social relations emphasising the most fundamental aspects of our political, legal and institutional structures. In terms of understanding health inequalities, Kaplan and Lynch have also argued for the importance of considering both horizontal and vertical social relations. ${ }^{35}$ This view in no way discounts the importance of informal social networks and their potential importance for public health - rather it places them in the broader context of vertical structures that impose limits on the way in which knowledge, resources and power can be deployed across those networks. The "mind set" of trust among people who agree to cooperate on a business venture, partly exists because contracts are enforced by law. The context of formal social relations is important in understanding how perceptions of trust and reciprocity are informally manifested. For authors like Szreter and Woolcock, government, legal and business organisations play a crucial part in structuring the nature of civil society where informal social relations, trust and reciprocity are played out. Szreter argues that "There is a major role for the state in fostering social capital through promoting equality of communicative competence and a participatory citizenship of mutual trust. This carries direct implications for the design of local government, education, social service and fiscal policy." (page 30). ${ }^{35}$ In contrast, Baum, has stated elsewhere that, "Most definitions agree that civil society is not market or government activity." (page 673). ${ }^{8}$ We disagree with Baum's summary of the available definitions, and think that such a circumscribed view of social capital will severely limit its potential relevance for public health.

\section{Conclusions}

The benevolent, evolutionary view of the epidemiological transition from mainly infectious to chronic diseases, which underlies models of social cohesion and social capital, has been used to justify the shift from material to psychosocial causes of health inequalities. ${ }^{5}$ We believe this approach is not warranted. Furthermore, it would seem difficult for a theory of population health based on psychosocial determination to accord with certain trends in population health. Well after the period of the epidemiological transition there have been impressive declines in mortality, especially from cardiovascular causes, in many countries like Finland, Britain, Japan, New Zealand and the USA. ${ }^{36}$ It is not likely these are the results of improved interpersonal networks and social support. ${ }^{14}$

Technological change in dynamic social systems makes assumptions about stable achievements in population health elusive at best. The late 20th century has witnessed how social factors have fuelled mortality because of wars; the resurgence of tuberculosis and the spread of new infectious diseases; large declines in life expectancy in parts of Eastern Europe and Africa; resistance to antibiotics; exposure to new environmental hazards; and the health threats of global warming. Without entering into an analysis of their political economic determinants, these public health problems require a substantial investment of material resources in rich as well as poor countries-an investment that concentration on psychosocial factors is likely to de-emphasise.

The concept of social capital is new for public health. We hope that as further debate ensues, the vision of social capital that is developed will embrace structural as well as interpersonal social relations. Otherwise, the rhetoric of social capital and social cohesion may run the risk of becoming a lament about "why can't we all just get along, like we are one big happy family?". This argument has been deployed by the political right many times and in many places-from justifying dismantling of the welfare state in Europe to curtailing active labour unions in the US. We are not one big happy family - there are the haves and the have nots; the exploiters and the exploited; the enfranchised and the disenfranchised. Our societies are divided by economic, racial, ethnic and gender inequalities that receive institutionalised political, legal and corporate sanctions. If we understand social capital as a societal-wide capacity for 
inclusiveness, human rights, social justice, and full political and economic participation, then indeed public health should invest.

Funding: none.

Conflicts of interest: none.

J LYNCH

Department of Epidemiology, School of Public Health, and the Institute for Social Research, University of Michigan, 109 Observatory Street, Ann Arbor, MI 48109-2029, USA

P DUE

Department of Social Medicine and Psychosocial Health, University of Copenhagen, Denmark

C MUNTANER

Institute of Occupational Health and Environmental Health, and Prevention Research Center, West Virginia University School of Medicine, USA

G DAVEY SMITH

Department of Social Medicine, University of Bristol

Correspondence to: Dr Lynch (jwlynch@umich.edu)

1 Baum F. Social Capital: Is it good for your health? Issues for a public health

agenda. F Epidemiol Community Health 1999;53:195-6.
2 Muntaner C, Lynch JW. Income inequality and social cohesion versus class Muntaner C, Lynch JW. Income inequality and social cohesion versus class
relations: A critique of Wilkinson's neo-Durkheimian research program. Int relations: A critique of Wilkinson's
f Health Services 1998;29:59-81.

3 Portes A. Social capital: Its origins and applications in modern sociology. Annu Rev Sociol 1998;24:1-24.

4 Marx K. Capital: a critique of political economy. Vols 1-3. Engels F, ed. [Translated by S Moore and E Aveling]. New York: International Publishers, 1967.

5 Cooper H, Arber S, Fee L, et al. The influence of social support and social capital on health. London: Health Education Authority, 1999.

6 Wilkinson RG. Unhealthy societies. The afflictions of inequality. London: Routledge, 1996.

7 Kawachi I, Kennedy BP, Lochner K, et al. Social capital, income inequality, and mortality. Am F Public Health 1997;87:1491-9.

8 Baum F. Public health and civil society: understanding and valuing the connection. Aust f Public Health 1997;21:673-5.

9 Woolcock M. Social capital and economic development: Toward a theoretical synthesis and policy framework. Theory and Society 1998;27:151-208.

10 Kunitz SJ, Levy JE. Navajo aging: the transition from family to institutional support. Tucson: University of Arizona Press, 1991.

11 Burg MM, Seeman TE. Families and health: the negative side of social ties. Ann Behav Med 1994;16:109-15.

12 O'Brien K, Wortman CB, Kessler RC, et al. Social relationships of men at O'Brien K, Wortman CB, Kessler RC, et al.
risk for AIDS. Soc Sci Med 1993;36:1161-7.

13 Due P, Holstein B, Lund R, Modvig J, Avlund K. Social relations: network, support and relational strain. Soc Sci Med 1999;48:661-73.
14 Davey Smith G, Egger M. Commentary: Understanding it all-health, metatheories, and mortality trends. BMF 1996;313:1584-5.

15 Wilkinson RG. Health inequalities: relative or absolute material standards. BMF 1997;314:591-5.

16 Pritchett L, Summers LH. Wealthier is healthier. F Human Resources 1997; 31:841-68.

17 Lynch JW, Kaplan GA, Pamuk E, et al. Income inequality and mortality in metropolitan areas of the United States. Am f Public Health 1998;88:107480

18 Inglehart R. Modernization and postmodernization. New Jersey: Princeton University Press, 1997.

19 Diener E, Diener M, Diener C. Factors predicting the subjective well-being of nations. F Personality Soc Psychol 1995;69:851-64.

20 Diener E, Sandvik E, Seidlitz L, et al. The relationship between income and subjective well-being: relative or absolute? Social Indicators Research 1993;28:195-223.

21 Sapolsky RM. Hormonal correlates of personality and social contexts: from non-human to human primates. In: Panter-Brick C, Worthman CM, eds. Hormones, health and behavior. New York: Cambridge University Press, 1999:18-46.

22 Adler NE, Boyce T, Chesney MA, et al. Socioeconomic status and health. The challenge of the gradient. Am Psychologist 1994;49:15-24.

23 Tarlov AR. Social determinants of health: the sociobiological translation. In: Blane D, Brunner E, Wilkinson R, eds. Health and social organization. London: Routledge, 1996.

24 Taylor SE, Repetti RL. What is an unhealthy environment and how does it get under the skin? Annu Rev Psychol 1997;48:411-47.

25 Boyle PJ, Gatrell AC, Duke-Wlliams O. The effects on morbidity of variability in deprivation and population stability in England and Wales: an investigation at small-area level. Soc Sci Med 1999;49:791-9.

26 Muntaner C, Eaton WW, Diala C, et al. Social class, assets, organizational control and the prevalence of common groups of psychiatric disorders. Soc Sci Med 1998;47:2043-53.

27 Davey Smith G. Income inequality and mortality: why are they related? Income inequality goes hand in hand with underinvestment in human resources. BMF 1996;312:987-8.

28 Lynch JW, Kaplan GA. Understanding how inequality in the distribution of income affects health. F Health Psychol 1997;2:297-314.

29 Federal Interagency Forum on Child and Family Statistics. America's children: key national indicators of well-being. Washington, DC: US Government Printing Office, 1998.

30 Davey Smith G, Shipley MJ, Rose G. Magnitude and causes of socioeconomic differentials in mortality: further evidence from the Whitehall study. F Epidemiol Community Health 1990;44:265-70

31 Macintyre S, Ellaway A, Der G, et al. Do housing tenure and car access predict health because they are simply markers of income or self esteem? A Scottish study. F Epidemiol Community Health 1998;52:657-64.

32 Blane D, Bartley M, Davey Smith G. Disease aetiology and materialist explanations of socioeconomic mortality differentials. Eur F Public Health 1997;7:385-91.

33 Lynch JW, Davey Smith G, Kaplan GA, et al. Income inequality and health: A neo- material interpretation. $B M \mathcal{F}$ (in press).

34 Szreter S. A new political economy for New Labour-The importance of social capital. Renewal 1999;7:30-44.

35 Kaplan GA, Lynch JW. Whither studies on the socioeconomic foundations of population health. Am F Public Health 1997;87:1409-11.

36 Beaglehole R. International trends in coronary heart disease mortality and incidence rates. $\mathcal{F}$ Cardiovasc Risk 1999;6:63-8. 